Published in final edited form as:

Angew Chem Int Ed Engl. 2009 ; 48(25): 4524-4527. doi:10.1002/anie.200805683.

\title{
Efficient Replication Bypass of Size-expanded DNA Base Pairs in Bacterial Cells ${ }^{\star *}$
}

\author{
Dr. James C. Delaney, \\ Departments of Chemistry and Biological Engineering, Massachusetts Institute of Technology \\ Cambridge, MA 02139 USA
}

Dr. Jianmin Gao,

Department of Chemistry, Stanford University, Stanford, CA 94305 USA

Dr. Haibo Liu,

Department of Chemistry, Stanford University, Stanford, CA 94305 USA

\author{
Nidhi Shrivastav, \\ Departments of Chemistry and Biological Engineering, Massachusetts Institute of Technology \\ Cambridge, MA 02139 USA
}

Prof. Dr. John M. Essigmann, and

Departments of Chemistry and Biological Engineering, Massachusetts Institute of Technology Cambridge, MA 02139 USA

Prof. Dr. Eric T. Kool

Department of Chemistry, Stanford University, Stanford, CA 94305 USA

John M. Essigmann: jessig@mit.edu; Eric T. Kool: kool@stanford.edu

\section{Keywords}

polymerase; xDNA; steric effects; fidelity; DNA repair

\begin{abstract}
One of the long-standing aims of biomimetic chemistry has been to develop molecules that function as much as possible as the natural ones do. ${ }^{[1]}$ Among the biopolymers, the nucleic acids have long served as a test bed for bio-inspired design. The earliest focus of altered structures for DNA was in the redesign of the phosphodiester backbone, ${ }^{[2]}$ and numerous studies found backbone variants that assembled well into helices. In addition, in recent years, some altered sugars have also been shown to be substrates for certain polymerase enzymes. ${ }^{[3]}$ Such work suggests the possibility of future biological activities associated with altered DNA backbones.

More recently, a number of laboratories have focused on design of replacements for the DNA bases themselves, which encode the chemical information of the cell. ${ }^{[4]}$ This is a challenging goal because biological enzymes have evolved the ability to manipulate these bases and base pairs with extraordinarily high selectivity. The polymerase replication of designed DNA pairs has been studied in a number of laboratories. Significant successes have been reported using varied strategies including base pairs with altered hydrogen
\end{abstract}

\footnotetext{
*** We thank the U.S. National Institutes of Health (CA80024 to JME and GM63587 to ETK) for support. JG and HL acknowledge Stanford Graduate Fellowships.

Correspondence to: John M. Essigmann, jessig@mit. edu; Eric T. Kool, kool@stanford.edu.

Supporting information for this article is available on the WWW under http://www.angewandte.org or from the author.
} 
bonding patterns, ${ }^{[4 \mathrm{a}]}$ pairs that lack hydrogen bonds altogether, ${ }^{[4 \mathrm{~b}-\mathrm{e}, \mathrm{i}, \mathrm{j}, \mathrm{m}-\mathrm{p}]}$ and pairs that have larger-than-natural dimensions. ${ }^{[4 q-\mathrm{s}, 5]}$ However, to date such designed base pairs have generally not been tested in living cells. One recent exception is a single isosteric replacement for a natural base that was replicated efficiently. ${ }^{[6]}$

Here we describe the first tests of a nonnatural DNA base pair geometry in a living cell. We have inserted single size-expanded DNA (xDNA) bases into phage genomes, and measured their replication in Escherichia coli cells. Surprisingly, although xDNA base pairs are considerably larger than the natural ones, we find that they are bypassed by the cellular replication machinery remarkably well. Indeed, two of the designed pairs possess biological function that is nearly indistinguishable from that of natural base pairs.

The four size-expanded DNA base pairs are shown in Fig. 1. The hydrogen-bonded pairs involve benzo-homologated bases opposite complementary natural partners, yielding base pairs $2.4 \AA$ larger than Watson-Crick pairs. ${ }^{[6]}$ The concept of a benzo-expanded base was first developed by Leonard, who developed lin-benzo-adenine and -guanine and studied them as ribonucleotide analogues three decades ago. ${ }^{[7]}$ We developed analogous benzopyrimidine $\mathrm{C}$-nucleosides and studied the ability of these four deoxynucleoside compounds $(\mathrm{xA}, \mathrm{xC}, \mathrm{xG}, \mathrm{xT})$ to form helices composed of expanded-size pairs. Work to date has shown that fully-substituted duplexes of xDNA pairs are highly stable and form right-handed helices with a backbone conformation resembling B-DNA. ${ }^{[5 a, d-f]}$ However, single xDNA pairs substituted within natural DNA are destabilizing, presumably because of the mismatch in size between the large pair and the naturally-sized backbone surrounding it. ${ }^{[5 \mathrm{~d}]}$ This could well present a challenge for a natural DNA polymerase, since such enzymes (especially explicative enzymes) can be highly sensitive to the sizes of base pairs. ${ }^{[6,8]}$ However, living cells possess several different specialized classes of polymerases, some of which function to bypass damaged bases that are often larger than those of normal DNA. ${ }^{[9]}$ Before completing extensive studies of in vitro replication of xDNA bases by natural and modified polymerases, we decided to test whether the cellular machinery already exists that might process these expanded bases.

We measured the information encoding capability of the single xDNA bases by incorporating them separately into oligonucleotides using standard phosphoramidite solidphase synthesis. ${ }^{[5 \mathrm{a}, \mathrm{c}]}$ The intact incorporation of expanded bases into the DNAs was confirmed by MALDI-TOF mass spectrometry in all cases (see Supporting Data). The oligonucleotides were then ligated into an M13mp7(L2) single-stranded viral genome. ${ }^{[10]}$ These modified genomes were then passaged through E. coli to quantify the biological responses. The responses to be derived are replication bypass efficiency (as scored by the amounts of daughter phage produced with respect to an unmodified competitor genome), and replication fidelity (measured by isolation and composition analysis of the daughter sequence, see below). A feature of this system is that there is no complementary strand opposite the unnatural bases in this single-stranded bacteriophage. This ensures that outcomes from replication and mutagenesis are derived solely from the initial replicative bypass of the modified bases, rather than from preferential replication of an opposing unmodified strand.

The ability of each of the four xDNA bases to support DNA replication in vivo was addressed using a competitive replication assay whereby genomes bearing a nonstandard base are mixed with a normal internal standard prior to electroporation into cells. ${ }^{[11]}$ The concentration of each xDNA base construct was determined in triplicate, followed by normalization and transfection using a 2:1 ratio of xDNA:competitor. The results showed that two of the four size-expanded bases were bypassed highly efficiently (Fig. 2). In E. coli that were not induced for a damage (SOS) response to translesion DNA replication, the xA 
and $\mathrm{xT}$ bases were bypassed with efficiencies that were, respectively, $80 \%$ and $73 \%$ that of the natural guanine control. The $\mathrm{xC}$ base was moderately well bypassed, with an efficiency of $29 \%$, while the signal dropped to $11 \%$ for the $\mathrm{xG}$ base. When UV light was used to induce the SOS response polymerases, bypass was improved by a significant amount in all cases, with $\mathrm{xA}$ and $\mathrm{xT}$ reaching the level of the unmodified guanine control. The $\mathrm{xC}$ base increased to $53 \%$, while the base that was the strongest block to replication, $\mathrm{xG}$, had the greatest response to the UV-induced SOS DNA polymerases, increasing to $45 \%$ relative to the phage genome containing a natural guanine base at the test site. This suggests that flexible damage-reponse enzymes may assist in the synthesis or extension of a large xDNA pair.

Having established that single xDNA base pairs can be processed by the $E$. coli replication machinery, we proceeded to evaluate which natural bases replaced the xDNA analogs in the daughter phage that were recovered, using a published restriction endonuclease/postlabeling assay. ${ }^{[10]}$ This serves as a quantitative measure of the ability of the bacterial polymerases to accurately read the chemical information encoded in the large-size bases. In the first round of DNA synthesis to produce the (-) strand of the phage DNA, a natural base would be incorporated opposite the xDNA base, thus making a size-expanded pair. In the next round, the all-natural DNA (-) strand would be replicated normally, producing new, all-naturallysubstituted (+)-strand daughter phage genomes that carry the sequence information encoded by the $\mathrm{xDNA}$ base at the original test site.

We found that two of the four xDNA bases, $\mathrm{xA}$ and $\mathrm{xC}$, encoded their analogous replacements correctly. The results are shown graphically in Figure 3. The fidelity of replacement of $\mathrm{xA}$ by $\mathrm{A}$ in the daughter phage is particularly striking, with $99 \%$ of the daughter phage containing adenine at the test site in the genome. This establishes that the xDNA-replicating polymerase correctly incorporates $\mathrm{T}$ opposite $\mathrm{xA}$ despite the large size of this pair. The $\mathrm{xC}$ analog was also read correctly the majority of the time, with replacement by $\mathrm{C}$ in $88 \%$ of the cases and by $\mathrm{A}$ (implicating $\mathrm{T}$-xC mispairing) in $10 \%$. The other two xDNA bases were read incorrectly, with $\mathrm{T}$ incorporation opposite both $\mathrm{xT}$ and $\mathrm{xG}$ being dominant over the "correct" xDNA pairing. Despite the misreading of $\mathrm{xG}$, its coding ambiguity was low, since it coded as A $95 \%$ of the time. We also carried out the same experiments with phage that had been passaged through $E$. coli in which the SOS response had been induced by UV light. The results showed (see Supporting Data) that this did not change the bases encoded by the large-sized bases significantly.

Although the $\mathrm{xA}$ and $\mathrm{xC}$ expanded bases are read correctly by the bacterial replication machinery, $\mathrm{xT}$ and $\mathrm{xG}$ are not, at least in this context. We speculate that the mispairings that are observed with these latter two bases arise from an alternative pairing geometry and from an alternative protonation state (Fig. S5). It is possible to pair T opposite xT with a geometry analogous to the T-G wobble, which may be closer to a Watson-Crick geometry. This might explain the observation of "correct" A-xT pairing only $26 \%$ of the time as compared with $73 \% \mathrm{~T}$-xT mispairing. As for the $\mathrm{xG}$ base, in some contexts it can be deprotonated at $\mathrm{pH}$ values neutral and higher. ${ }^{[5 f]}$ If this occurred during replication it would present a structure that is more complementary to $\mathrm{T}$ than $\mathrm{C}$. We note that although two xDNA bases are incorrectly processed in this context, this still leaves a substantial information-encoding capability. The correct coding of two xDNA pairs involves four different bases, which is, in principle, the same amount of information content as the natural genetic system.

The finding of efficient replication for two of the large-sized pairs is surprising, given that replicative polymerases can be highly sensitive to nucleobase size. ${ }^{[8]}$ To examine this in more detail we carried out preliminary in vitro experiments with DNA Polymerase I (Klenow fragment (Kf)), the most extensively studied of the $E$. coli polymerases. We used 
28mer DNA templates containing a single xDNA base immediately downstream of a primer. To evaluate enzymatic efficiency and selectivity, we performed steady-state kinetics measurements of the addition of single natural nucleotides opposite each of these large bases. The results are given in Table 1 .

The kinetics data confirm that at least one natural enzyme can correctly read sequence information stored in size-expanded bases. Not surprisingly, the Kf enzyme is inefficient in constructing these large base pairs, with $\mathrm{V}_{\max } / \mathrm{K}_{\mathrm{m}}$ values ca. 100-1000-fold below those for a natural base pair. Interestingly, this polymerase selectively chose the correct pairing partner with each of the four xDNA bases. Moreover, preliminary experiments on extension of an xDNA pair by this enzyme also show selective bypass of a correct pair over mismatched ones, again with very low efficiency (see Supporting Data). It appears that enzyme(s) other than Pol I are responsible for the efficient replication of $\mathrm{xG}$ and $\mathrm{xT}$ in vivo since these bases exhibited different cellular coding efficiencies (Fig. 3). It will be of interest in the future to explore the other classes of polymerases, including types that are functionally more flexible, ${ }^{[12]}$ to evaluate which are able to efficiently replicate such large pairs. It will also be important to study the replication in new sequence contexts, and to evaluate exonuclease proofreading of such pairs.

Taken together, the results show (a) that a DNA polymerase is able read the chemical information stored in the size-expanded bases, and (b) that the full replication machinery of E. coli is able to recognize the sequence encoded by two of the xDNA bases correctly and efficiently. This intriguing outcome suggests that it may be possible in the future to incorporate multiple $\mathrm{xA}$ or $\mathrm{xC}$ bases into phage genomes, or to incorporate $\mathrm{xDNA}$ pairs into plasmids that encode protein expression. In addition, it would be of interest to explore whether other organisms might also possess the ability to read xDNA pairs. The findings may ultimately lead to new strategies for modifying biological systems in useful ways.

\section{Experimental Section}

\section{Synthesis of modified nucleosides and oligonucleotides}

The deoxynucleoside phosphoramidite derivatives of $\mathrm{xA}, \mathrm{xT}, \mathrm{xC}$, and $\mathrm{xG}$ were prepared as described previously. ${ }^{[5 a-c]}$ They were incorporated into oligodeoxynucleotides using the published methods, and were purified by HPLC and characterized by MALDI-TOF mass spectrometry (see Supporting Data).

\section{Methods for enzyme kinetics}

28-nt oligonucleotides containing single $\mathrm{xA}, \mathrm{xC}, \mathrm{xG}, \mathrm{xT}$ residues were prepared along with a 23-nt complementary primer, which was labeled at its $5^{\prime}$ end with ${ }^{32} \mathrm{P}$. Polymerase reaction conditions were as follows: DNA concentration $5 \mu \mathrm{M}$ in a $37^{\circ} \mathrm{C}$ buffer containing $100 \mathrm{mM}$ Tris $\bullet \mathrm{HCl}$ (pH 7.5), $20 \mathrm{mM} \mathrm{MgCl} 2,2 \mathrm{mM}$ dithiothreitol, and $0.1 \mathrm{mg} / \mathrm{mL}$ acetylated BSA. Enzyme and nucleotide concentrations were varied. Details of methods are given in the Supporting Data file.

\section{Methods for cellular assays}

The Competitive Replication of Adduct Bypass (CRAB) assay ${ }^{[10 b]}$ was used to determine the replication blocking (if any) by the size-expanded bases in M13 phage. Figure S1 shows an outline of the assay. Quantification of the modified and control phage sequences is performed on the daughter phage population as described. The Restriction Endonuclease And Postlabeling determination of mutation frequency (REAP) assay ${ }^{[10 b]}$ quantifies the type and amount of mutagenesis at the modified base site by obtaining the base composition at that position after cellular replication (Fig. S1). After PCR amplification, products are 
cleaved, labeled and enzymatically digested, then analyzed by TLC and quantified by phosphorimagery. Experiments were performed in triplicate.

\section{Supplementary Material}

Refer to Web version on PubMed Central for supplementary material.

\section{References}

1. a) Breslow R. Pure Appl Chem. 1998; 70:267-270.b) Kool ET, Waters ML. Nat Chem Biol. 2007; 3:70-73. [PubMed: 17235337]

2. a) Murakami A, Blake KR, Miller PS. Biochemistry. 1985; 24:4041-4046. [PubMed: 2413882] b) Neilsen PE, Egholm M, Berg RH, Buchardt O. Science. 1991; 254:1497-1500. [PubMed: 1962210] c) Nielsen P, Pfundheller HM, Wengel J. Chem Commun. 1997:825-826.d) Lescrinier E, Esnouf R, Schraml J, Busson R, Heus H, Hilbers C, Herdewijn P. Chem Biol. 2000; 7:719-731. [PubMed: 10980452] e) Egli M, Pallan PS, Pattanayek R, Wilds CJ, Lubini P, Minasov G, Dobler M, Leumann CJ, Eschenmoser A. J Am Chem Soc. 2006; 128:10847-10856. [PubMed: 16910680] f) Schöning K, Scholz P, Guntha S, Wu X, Krishnamurthy R, Eschenmoser A. Science. 2000; 290:1347-1351. [PubMed: 11082060]

3. a) Chaput JC, Szostak JW. J Am Chem Soc. 2003; 125:9274-9275. [PubMed: 12889939] b) Shaw BR, Dobrikov M, Wang X, Wan J, He K, Lin JL, Li P, Rait V, Sergueeva Z, Sergueev D. Ann N Y Acad Sci. 2003; 1002:12-29. [PubMed: 14751819] c) Pochet S, Kaminski PA, Van Aerschot A, Herdewijn P, Marlière P. C R Biol. 2003; 326:1175-1184. [PubMed: 14746272] d) Sinha S, Kim PH, Switzer C. J Am Chem Soc. 2004; 126:40-41. [PubMed: 14709049] e) Jung KH, Marx A. Cell Mol Life Sci. 2005; 62:2080-2091. [PubMed: 16041567] f) Veedu RN, Vester B, Wengel J. Nucleosides Nucleotides Nucl Acids. 2007; 26:1207-1210.

4. a) Piccirilli JA, Krauch T, Moroney SE, Benner SA. Nature. 1990; 343:33-37. [PubMed: 1688644] b) Moran S, Ren RXF, Rumney S, Kool ET. J Am Chem Soc. 1997; 119:2056-2057. [PubMed: 20737028] c) Matray TJ, Kool ET. Nature. 1999; 399:704-708. [PubMed: 10385125] d) Tae EL, Wu Y, Xia G, Schultz PG, Romesberg FE. J Am Chem Soc. 2001; 123:7439-7340. [PubMed: 11472182] e) Parsch J, Engels JW. Nucl Acids Res. 2001; 20:815-818.f) Weizman H, Tor Y. J Am Chem Soc. 2001; 123:3375-3376. [PubMed: 11457077] g) Beuck C, Singh I, Bhattacharya A, Hecker W, Parmar VS, Seitz O, Weinhold E. Angew Chem Int Ed. 2003; 42:3958-3960.h) Paul N, Nashine VC, Hoops G, Zhang P, Zhou J, Bergstrom DE, Davisson VJ. Chem Biol. 2003; 10:815825. [PubMed: 14522052] i) Henry AA, Romesberg FE. Curr Opin Chem Biol. 2003; 7:727-733. [PubMed: 14644182] j) Hirao I, Harada Y, Kimoto M, Mitsui T, Fujiwara T, Yokoyama S. J Am Chem Soc. 2004; 126:13298-13305. [PubMed: 15479084] k) Zhang X, Lee I, Zhou X, Berdis AJ. J Am Chem Soc. 2006; 128:143-149. [PubMed: 16390141] 1) Moore CL, Zivkovic A, Engels JW, Kuchta RD. Biochemistry. 2004; 43:12367-12374. [PubMed: 15379576] m) Hirao I. Curr Opin Chem Biol. 2006; 10:622-627. [PubMed: 17035074] n) Zahn A, Leumann CJ. Bioorg Med Chem. 2006; 14:6174-6188. [PubMed: 16784866] o) Hwang GT, Romesberg FE. J Am Chem Soc. 2008; 130:14872-14882. [PubMed: 18847263] p) Hirao I, Mitsui T, Kimoto M, Yokoyama S. J Am Chem Soc. 2006; 129:15549-15555. [PubMed: 18027940] q) Hikishima S, Minakawa N, Kuramoto K, Fujisawa Y, Ogawa M, Matsuda A. Angew Chem Int Ed. 2005; 44:596-598.r) Battersby TR, Albalos M, Friesenhahn MJ. Chem Biol. 2007; 14:525-531. [PubMed: 17524983] s) Doi Y, Chiba J, Morikawa T, Inouye MJ. J Am Chem Soc. 2008; 130:8762-8768. [PubMed: 18543918]

5. a) Liu H, Gao J, Lynch SR, Maynard L, Saito D, Kool ET. Science. 2003; 302:868-871. [PubMed: 14593180] b) Liu H, Gao J, Maynard L, Saito YD, Kool ET. J Am Chem Soc. 2004; 126:11021109. [PubMed: 14746479] c) Gao J, Liu H, Kool ET. Angew Chem Int Ed. 2005; 44:3118-3122.d) Gao J, Liu H, Kool ET. J Am Chem Soc. 2004; 126:11826-11831. [PubMed: 15382917] e) Liu H, Lynch SR, Kool ET. J Am Chem Soc. 2004; 126:6900-6905. [PubMed: 15174859] f) Lynch SR, Liu H, Gao J, Kool ET. J Am Chem Soc. 2006; 128:14704-14711. [PubMed: 17090058]

6. Kim TW, Delaney JC, Essigmann JM, Kool ET. Proc Natl Acad Sci USA. 2005; 102:15803-15808. [PubMed: 16249340]

7. a) Scopes DI, Barrio JR, Leonard NJ. Science. 1977; 195:296-298. [PubMed: 188137] b) Leonard NJ. Acc Chem Res. 1982; 15:128-135. 
8. Kim TW, Brieba LG, Ellenberger T, Kool ET. J Biol Chem. 2006; 281:2289-2295. [PubMed: 16311403]

9. a) Nohmi T. Ann Rev Microbiol. 2006; 60:231-253. [PubMed: 16719715] (b) Jarosz DF, Godoy VG, Walker GC. Cell Cycle. 2007; 6:817-822. [PubMed: 17377496]

10. a) Delaney JC, Essigmann JM. Chem Biol. 1999; 6:743-753. [PubMed: 10508678] b) Delaney JC, Essigmann JM. Methods Enzymol. 2006; 408:1-15. [PubMed: 16793359]

11. Delaney JC, Essigmann JM. Proc Natl Acad Sci USA. 2004; 101:14051-14056. [PubMed: 15381779]

12. Mizukami S, Kim TW, Helquist SA, Kool ET. Biochemistry. 2006; 45:2772-2778. [PubMed: 16503632] 


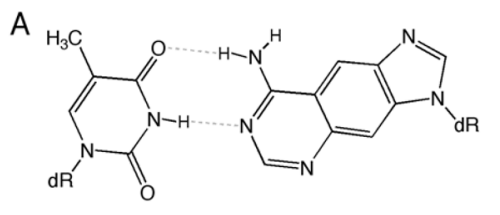

$\mathbf{T}-\mathbf{x A}$

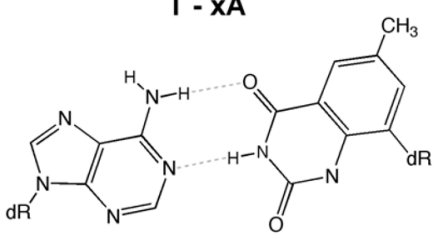

$A-\mathbf{x} T$
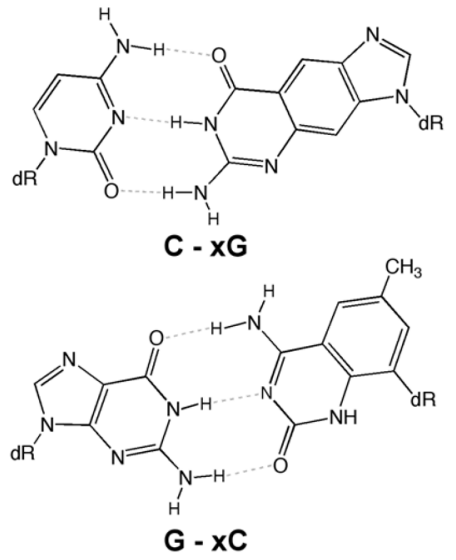

B

$$
\text { 5' - GAAGACCT X GGCGTCC - 3' }
$$

Figure 1.

Structures and DNA sequence in this study. A. Structures of the four xDNA bases evaluated in cellular replication, with their paired structures shown. B. DNA sequence context for xDNA bases (at position X) inserted into single-stranded M13 bacteriophage. 


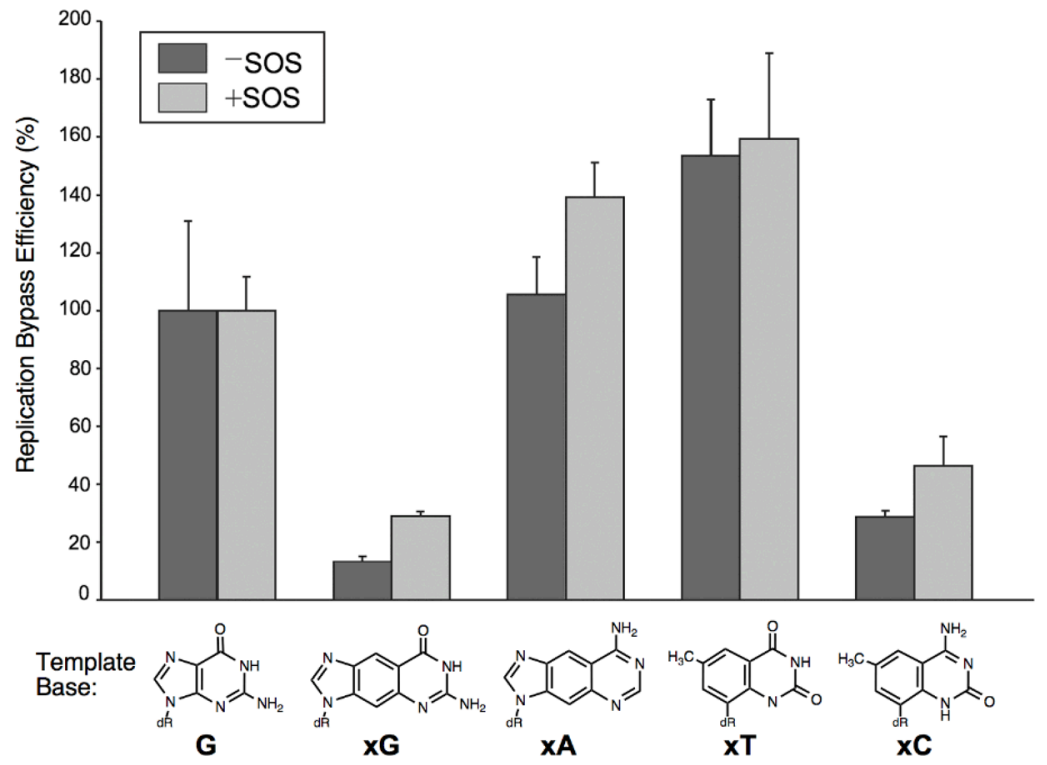

Figure 2.

The efficiency of replication bypass of single xDNA bases in vivo. Bases were ligated into single-stranded M13 bacteriophage and replicated in E. coli. Bypass efficiency was measured by quantifying relative output signals from test and internal standard genomes, and normalizing to those from the $\mathrm{G}$ at the test site control. 


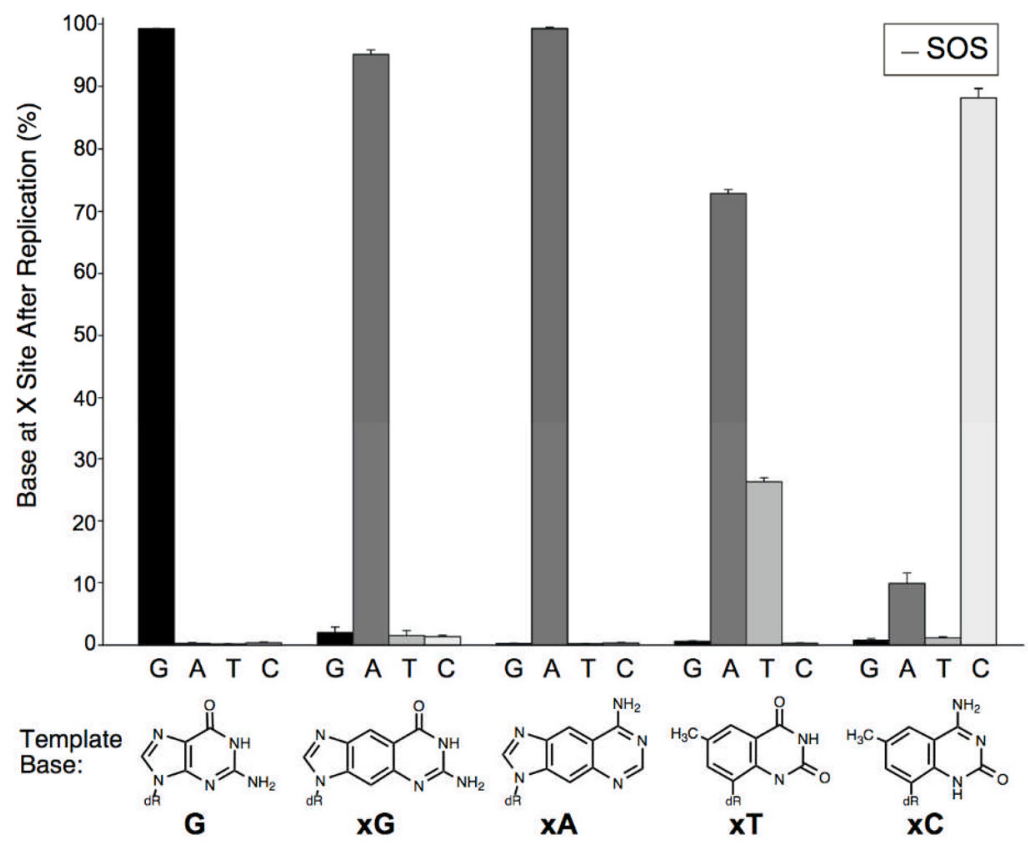

Figure 3.

The replicative encoding capability of single xDNA bases in E. coli. Shown are the relative amounts of each natural base at the test site $(\mathrm{X})$ that replaced the xDNA base shown after phage replication. 


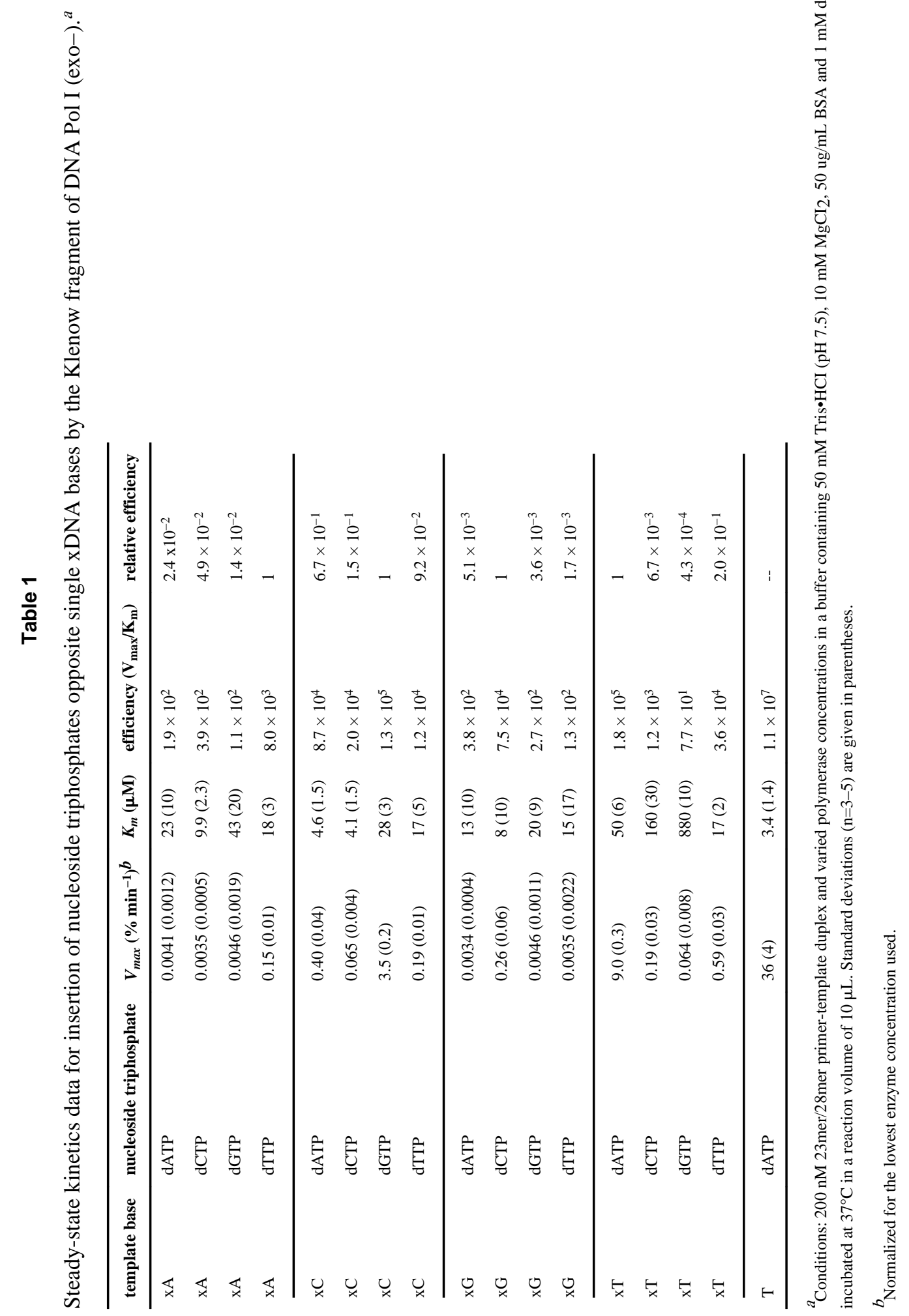

